\title{
Correction to: Assessment of cervical spine involvement in rheumatoid arthritis patients in the era of biologics: a real-life, cross-sectional MRI study
}

\author{
Csaba Oláh ${ }^{1,4} \cdot$ Zsófia Kardos $^{2} \cdot$ László Kostyál $^{3} \cdot$ Katalin Hodosi ${ }^{4}$ - László Tamási • Dániel Bereczki ${ }^{5}$. \\ Zoltán Szekanecz ${ }^{4}$ (D)
}

Published online: 4 April 2020

(c) Springer-Verlag GmbH Germany, part of Springer Nature 2020

\section{Correction to: Rheumatology International https://doi.org/10.1007/s00296-020-04549-w}

In the original article, the first author's given name and family name were interchanged as provided by the authors in the original manuscript. The correct given name and family name is Csaba Oláh.

The original article has been corrected.

Publisher's Note Springer Nature remains neutral with regard to jurisdictional claims in published maps and institutional affiliations.

The original article can be found online at https://doi.org/10.1007/ s00296-020-04549-w.

Zoltán Szekanecz

szekanecz.zoltan@med.unideb.hu

Csaba Oláh

olahcs@gmail.com

Zsófia Kardos

dr.kardos.zsofia@gmail.com

László Kostyál

kostyalfed@gmail.com

Katalin Hodosi

khodosi@gmail.com

László Tamási

ltamasi01@gmail.com

Dániel Bereczki

bereczki.daniel@med.semmelweis-univ.hu
Department of Neurosurgery, Borsod County Teaching Hospital, Miskolc, Hungary

2 Department of Rheumatology, Borsod County Teaching Hospital, Miskolc, Hungary

3 Department of Radiology, Borsod County Teaching Hospital, Miskolc, Hungary

4 Division of Rheumatology, Faculty of Medicine, University of Debrecen, Nagyerdei str 98, Debrecen 4032, Hungary

5 Department of Neurology, Semmelweis University, Budapest, Hungary 